\title{
The Prevalence of Methicillin-Resistant Staphylococcus aureus Colonization in Patients with Complicated Skin and Skin Structure Infections after Treatment with Linezolid or Vancomycin
}

\author{
Laura A. Puzniak1, Kimbal D. Ford2', David B. Huang1 \\ ${ }^{1}$ formerly Pfizer Inc., Collegeville, USA \\ ${ }^{2}$ Pfizer Inc., Collegeville, USA \\ Email: kimbal.d.ford@pfizer.com
}

Received 25 September 2014; revised 10 November 2014; accepted 25 November 2014

Copyright (C) 2014 by authors and Scientific Research Publishing Inc.

This work is licensed under the Creative Commons Attribution International License (CC BY). http://creativecommons.org/licenses/by/4.0/

(c) (i) Open Access

\begin{abstract}
Background: Complicated skin and skin structure infections (cSSSIs) due to Staphylococcus aureus, including methicillin-resistant $S$. aureus (MRSA), are associated with significant morbidity. Reducing MRSA carriage has been a focus of infection control interventions. The prevalence of MRSA colonization after successful treatment of a MRSA cSSSI is unknown. Methods: Secondary analysis of a randomized controlled trial comparing linezolid and vancomycin for the treatment of MRSA cSSSI. Adult patients that had a colonization culture, confirmed MRSA cSSSI, received at least one dose of study treatment, and had an outcome recorded at end of study. Patient, clinical characteristics and prevalence of colonization were compared by treatment regimens. A multivariate regression model identified predictors of MRSA colonization at EOS. Results: There were 456 patients evaluated. The prevalence of MRSA colonization was higher for vancomycin treated patients compared to linezolid treated patients at end of treatment (EOT) $(28 \%$ vs. $5 \%, p<0.001)$ and EOS $(34 \%$ vs. $22 \%, p<0.01)$. Independent predictors of colonization at EOS after treatment for a MRSA cSSSI included diagnosis, primarily driven by abscess, black race, treatment with vancomycin, MRSA mixed infection and male gender. Conclusion: Patients treated with linezolid for a cSSSI had less MRSA colonization at EOT and EOS compared to those treated with vancomycin. Multiple independent predictors of MRSA colonization were identified. Additional studies evaluating the relationship of MRSA colonization after treatment of cSSSI are needed.
\end{abstract}

\section{Keywords}

Staphylococcus aureus, Complicated Skin and Skin Structure Infection, Colonization, Linezolid, 


\section{Vancomycin}

\section{Introduction}

Staphylococcus aureus, including methicillin-resistant S. aureus (MRSA), is a prominent nosocomial and community pathogen causing complicated skin and skin structure infections (cSSSI) [1] [2]. Approximately 30\% of the human population is colonized with S. aureus in their nasal passages [3] [4]. Multiple studies have shown an association between $S$. aureus or MRSA colonization and subsequent infection [4]-[8].

MRSA colonization is a reservoir for horizontal transmission both within the hospital setting and in the community [4] [9] [10]. When host immune defenses are impaired, colonization may result in infection [4] [5]. As a result, infection control interventions have focused on reducing MRSA carriage as a way to control the transmission of MRSA [11] [12]. However, the efficacy and cost effectiveness of these strategies vary by study. There is a lack of consensus regarding optimal screening and decolonization strategies to prevent infections in persons colonized with MRSA [4] [10] [13]-[18].

The prevalence of MRSA colonization after successful treatment of a MRSA cSSSI is unknown. In addition, it is unknown whether colonization with MRSA affects the outcomes of treatment of a MRSA cSSSI or the extent that treatment with an anti-MRSA agent affects colonization status. If certain treatment regimens diminish colonization, even if it is transient, this could impact the resolution of the infection while also reducing horizontal transmission and recurrence.

The aims of this study were: 1) To determine the prevalence of MRSA colonization among patients treated with linezolid or vancomycin for MRSA cSSSI; and 2) To identify predictors of MRSA colonization.

\section{Methods}

\subsection{Study Design}

This analysis used data from a prospective, open-labeled, comparator-controlled, multicenter, Phase 4 trial (NCT00087490) that occurred from 2004-2007, evaluating the efficacy of linezolid and vancomycin in the treatment of MRSA cSSSI. Patients received either linezolid $600 \mathrm{mg}$ intravenously (IV) or orally every $12 \mathrm{~h}$ or IV vancomycin $15 \mathrm{mg} / \mathrm{kg}$ every $12 \mathrm{~h}$ (dose adjusted for creatinine clearance) for 7 - 14 days [19]. Patients with documented MRSA bacteremia could receive up to 21 days of therapy at the discretion of the investigator with prior approval from the medical monitor. Based on the protocol, nares and groin cultures were obtained at EOT and EOS [19].

\subsection{Patient Population and Assessment}

Adult patients meeting the primary study's modified intent to treat population (mITT), which was defined as patients receiving at least 1 dose of study medication and culture confirmed MRSA, who also had a colonization culture (nares and/or groin) at end of treatment (EOT) and end of study (EOS), defined as 6 - 28 days after EOT were considered the study population for this analysis [19].

Demographics and patient characteristics were compared separately for two cohorts: 1) Colonization comparison, comparing those that were MRSA colonized versus those who were not MRSA colonized at EOT and EOS, and 2) Treatment comparison, comparing linezolid versus vancomycin treated patients by MRSA colonization or no MRSA colonization at EOT and EOS.

\subsection{Study Definitions}

Inclusion criteria: Patients were included in the primary trial if they had signs or symptoms of a cSSSI involving deep tissues and at least two of the following: purulent drainage, erythema, swelling or induration, tenderness or pain, and local warmth. In addition, patients had at least one sign of systemic infection, such as fever, hypotension, increased white blood cell count $\left(\geq 10,000 \mathrm{~mm}^{3}\right)$, or more than $15 \%$ immature neutrophils regardless of the total peripheral white blood cell count. Specific enrollment criteria were applied for patients with diabetic foot infections, which included evidence of a deep infection extending below the subcutaneous tissue of the foot, an- 
kle, or lower leg that required a surgical procedure or an identifiable wound [19].

Exclusion criteria: Patients were excluded from the primary clinical trial if there was known or suspected necrotizing fasciitis, gangrene, septic arthritis, osteomyelitis, or who were previously treated with a MRSA-active antibiotic (systemic or topical) for more than 24 hours and within 72 hours of receiving first dose of study drug [19].

Colonization Cultures: A sterile swab from culturette moistened with transport media was used to obtain MRSA cultures from the nares and groin.

\subsection{Statistical Analysis}

Statistical comparisons between groups were performed using the Chi-square test or Fisher's Exact test for categorical variables and ANOVA or t-test for continuous variables. We constructed risk differences with 2-sided 95\% confidence intervals (CI) of MRSA colonization after treatment with linezolid compared to vancomycin; $p$ $\leq 0.05$ was considered statistically significant.

Backwards multivariate logistic regression was used to identify factors that were significantly related to MRSA colonization at EOS. The regression was built using criteria of $p \leq 0.10$ and $p \leq 0.05$ to remain in different iterations of possible models. Covariate reduction techniques were applied prior to model building including near zero variance (NZV), missingness, and covariate correlations, associations, and clusters. In addition, 1000 bootstrap samples were generated to check the model results for all models, including the final model chosen. The validity of the final model was checked with the Hosmer-Lemeshow goodness-of-fit test.

\section{Results}

There were 640 subjects in the primary study mITT population. Of these, 456 patients had a colonization culture at EOS (linezolid treated $=239$ and vancomycin treated $=217$ ) and comprised the study population. There were 414 patients (linezolid $=220$ and vancomycin $=194$ ) that had a colonization culture at EOT. Table 1 describes the patient and clinical characteristics by colonization status at end of study for patients treated for a MRSA cSSSI. There were no differences in baseline characteristics between those treated with linezolid or vancomycin. There were significant differences in the frequency of primary diagnosis between those patients colonized and not colonized at EOS. Specifically, the majority of patients colonized at EOS had an abscess 76 (60.8\%) compared to those not colonized 152 (45.9\%). Patients with ulcers and surgical wounds had similar frequency of colonization. Patients who were not colonized $(n=44,13.3 \%)$ had more "other" diagnosis which included blister, erysipelas, bursitis, haematoma, insect bite and burn infections compared to those colonized $(n=3,2.4 \%)$.

The prevalence of MRSA colonization at EOT and EOS was $15.5 \%$ and $27.4 \%$, respectively. Patients receiving linezolid were significantly less likely to be colonized at EOT, compared to those treated with vancomycin ( $4.5 \%$ vs. $27.8 \%, p<0.01$ ). This trend remained significant at EOS with $21.8 \%$ of linezolid patients being colonized versus $33.6 \%$ of patients receiving vancomycin $(p<0.01)$.

Patients were more frequently colonized in the nares compared to the groin at both EOT and EOS (75\% vs. $45 \%, p<0.05$; and $73 \%$ vs. $63 \%, p<0.05$, respectively). Patients were colonized at both sites $20 \%$ of the time at EOT and 36\% at EOS. There were 16 (25\%) and 34 (27\%) patients colonized in the groin, but not in the nares at EOT and EOS, respectively.

Patients treated with linezolid had significantly less colonization at the nares, groin and both sites compared to vancomycin treated patients, $p<0.01$ for all observations at EOT. At EOS, linezolid treated patients had significantly less colonization overall, primarily driven by differential colonization rates in the nares, $p<0.05$.

Figure 1 illustrates microbiologic outcomes at EOT and EOS by colonization status and treatment. Patients treated with linezolid had a significantly greater microbiological success rate than patients treated with vancomycin at EOT among those colonized as well as those not colonized.

There were no differences in clinical success rates at EOT by treatment or by colonization status. However, there was a significant difference in clinical success rates for linezolid treated patients compared to vancomycin treated patients among those not colonized (RD: 8.7, 95\% CI: 0.2, 17.1) at EOS.

Table 2 describes results from the multivariate model. Independent predictors of colonization at EOS after treatment for a MRSA cSSSI included diagnosis, primarily abscess, black race, treatment with vancomycin, MRSA mixed infection and male gender. The best fit model was adjusted for diabetes and vascular status. 
Table 1. Patient and clinical characteristics by colonization status at end of study for patients treated for a cSSSI.

\begin{tabular}{|c|c|c|c|c|c|c|c|}
\hline \multirow{2}{*}{ Characteristic } & \multicolumn{3}{|c|}{ Colonized $(n=125)$} & \multicolumn{3}{|c|}{ Not Colonized $(\mathrm{n}=331)$} & \multirow{2}{*}{$\begin{array}{c}\text { Colonized vs. } \\
\text { Not Colonized } \\
\text { P Value }\end{array}$} \\
\hline & $\begin{array}{l}\text { Linezolid } \\
\text { (n= 52) }\end{array}$ & $\begin{array}{l}\text { Vancomycin } \\
\quad(\mathrm{n}=73)\end{array}$ & $P$ Value & $\begin{array}{l}\text { Linezolid } \\
(\mathrm{n}=187)\end{array}$ & $\begin{array}{l}\text { Vancomycin } \\
(\mathrm{n}=144)\end{array}$ & $P$ Value & \\
\hline Age, Mean (SD), y & $45.9(19.4)$ & 49.7 (16.3) & 0.24 & $49.8(17.4)$ & $49.3(19.1)$ & 0.80 & 0.44 \\
\hline Gender, Male, n (\%) & $31(59.6)$ & $49(67.1)$ & 0.45 & $100(53.5)$ & $78(54.2)$ & 0.91 & 0.06 \\
\hline $\begin{array}{l}\text { Race, n (\%) } \\
\text { White } \\
\text { Black } \\
\text { Asian } \\
\text { Other }\end{array}$ & $\begin{array}{c}35(67.3) \\
10(19.2) \\
0 \\
7(13.5)\end{array}$ & $\begin{array}{c}50(68.5) \\
16(21.9) \\
0 \\
7(9.6)\end{array}$ & 0.77 & $\begin{array}{c}135(72.2) \\
26(13.9) \\
2(1.1) \\
24(12.8)\end{array}$ & $\begin{array}{c}95(66.0) \\
16(11.1) \\
2(1.4) \\
31(21.5)\end{array}$ & 0.19 & 0.06 \\
\hline Weight, kg (SD) & $89.8(36.9)$ & $83.8(23.6)$ & 0.27 & $85.8(24.8)$ & $82.1(29.1)$ & 0.21 & 0.47 \\
\hline Prior Hospitalization, n (\%) & $23(44.2)$ & $28(38.4)$ & 0.58 & 77 (41.2) & 63 (43.8) & 0.66 & 0.83 \\
\hline $\begin{array}{c}\text { Route of Initial Treatment, n (\%) } \\
\text { IV } \\
\text { Oral }\end{array}$ & $\begin{array}{l}27(51.9) \\
25(48.1)\end{array}$ & $\begin{array}{c}73(100) \\
0\end{array}$ & $<0.01$ & $\begin{array}{l}103(55.1) \\
84(44.9)\end{array}$ & $\begin{array}{c}144(100) \\
0\end{array}$ & $<0.01$ & 0.27 \\
\hline $\begin{array}{c}\text { Concomitant Gram-Negative } \\
\text { Coverage, } \mathrm{n}(\%)\end{array}$ & $29(55.8)$ & 35 (47.9) & 0.47 & $80(42.8)$ & $68(47.2)$ & 0.44 & 0.25 \\
\hline Corticosteroid Receipt, n (\%) & $5(9.6)$ & $5(6.8)$ & 0.74 & $10(5.3)$ & $11(7.6)$ & 0.50 & 0.54 \\
\hline Immunosuppressant Receipt, n (\%) & 0 & 0 & & $1(0.5)$ & $1(0.7)$ & 1.0 & 1.0 \\
\hline $\begin{array}{c}\text { Primary Diagnosis, n (\%) } \\
\text { Abscess } \\
\text { Ulcer } \\
\text { Surgical Wound } \\
\text { Other }\end{array}$ & $\begin{array}{c}30(57.7) \\
7(13.5) \\
12(23.1) \\
3(5.8)\end{array}$ & $\begin{array}{c}46(63.0) \\
11(15.1) \\
14(19.2) \\
2(2.7)\end{array}$ & 0.77 & $\begin{array}{l}88(47.1) \\
33(17.6) \\
39(20.9) \\
27(14.4)\end{array}$ & $\begin{array}{l}64(44.4) \\
23(16.0) \\
38(26.4) \\
19(13.2)\end{array}$ & 0.70 & $<0.01$ \\
\hline $\begin{array}{c}\text { Comorbidities } \\
\text { Diabetes } \\
\text { Cardiac } \\
\text { Immune System Disorders } \\
\text { Psychiatric Disorders } \\
\text { Respiratory Disorders } \\
\text { Vascular Disorders }\end{array}$ & $\begin{array}{l}16(30.8) \\
11(21.2) \\
11(21.2) \\
20(38.5) \\
10(19.2) \\
21(40.4)\end{array}$ & $\begin{array}{l}27(37.0) \\
14(19.2) \\
11(15.1) \\
26(35.6) \\
12(16.4) \\
32(43.8)\end{array}$ & $\begin{array}{l}0.57 \\
0.82 \\
0.48 \\
0.85 \\
0.81 \\
0.72\end{array}$ & $\begin{array}{l}56(29.9) \\
45(24.1) \\
40(21.4) \\
72(38.5) \\
45(24.1) \\
101(54.0)\end{array}$ & $\begin{array}{l}41(28.5) \\
35(24.3) \\
26(18.1) \\
41(28.5) \\
32(22.2) \\
63(43.8)\end{array}$ & $\begin{array}{c}0.80 \\
1.0 \\
0.49 \\
0.06 \\
0.79 \\
0.08\end{array}$ & $\begin{array}{l}0.30 \\
0.38 \\
0.69 \\
0.66 \\
0.20 \\
0.48\end{array}$ \\
\hline $\begin{array}{l}\text { Isolated Pathogens, n (\%) } \\
\text { MRSA Only } \\
\text { MRSA Mixed Infection }\end{array}$ & $\begin{array}{l}36(69.2) \\
16(30.8)\end{array}$ & $\begin{array}{l}53(72.6) \\
20(27.4)\end{array}$ & 0.69 & $\begin{array}{c}142(75.9) \\
45(24.1)\end{array}$ & $\begin{array}{l}105(72.9) \\
39(27.1)\end{array}$ & 0.61 & 0.48 \\
\hline
\end{tabular}

\section{Discussion}

In this study, patients treated with linezolid compared to vancomycin for a cSSSI had less MRSA colonization at EOT and EOS. These findings may be explained by the level of tissue penetration of linezolid [20] [21]. Pharmacokinetic studies demonstrate that linezolid reaches peak concentrations rapidly with an absolute bioavailability that exceeds $100 \%$ and penetrates well into perfused body spaces including skin blister fluid [21]. Vancomycin possesses a complex pharmacokinetic profile and its skin penetration is variable and may be affected by inflammation and patient comorbidities [22].

Although linezolid compared to vancomycin treated patients had less MRSA carriage, complete eradication of colonization immediately following treatment was not observed. These results may be due to the fact that benefits from treatment may be transient on carriage, which is similar to what is seen with the use of mupirocin [4] [12] or related to the fact that for about $20 \%$ of the general population, S. aureus carriage is persistent and represents a balanced microbiota for that person [5] [7] [23]. 


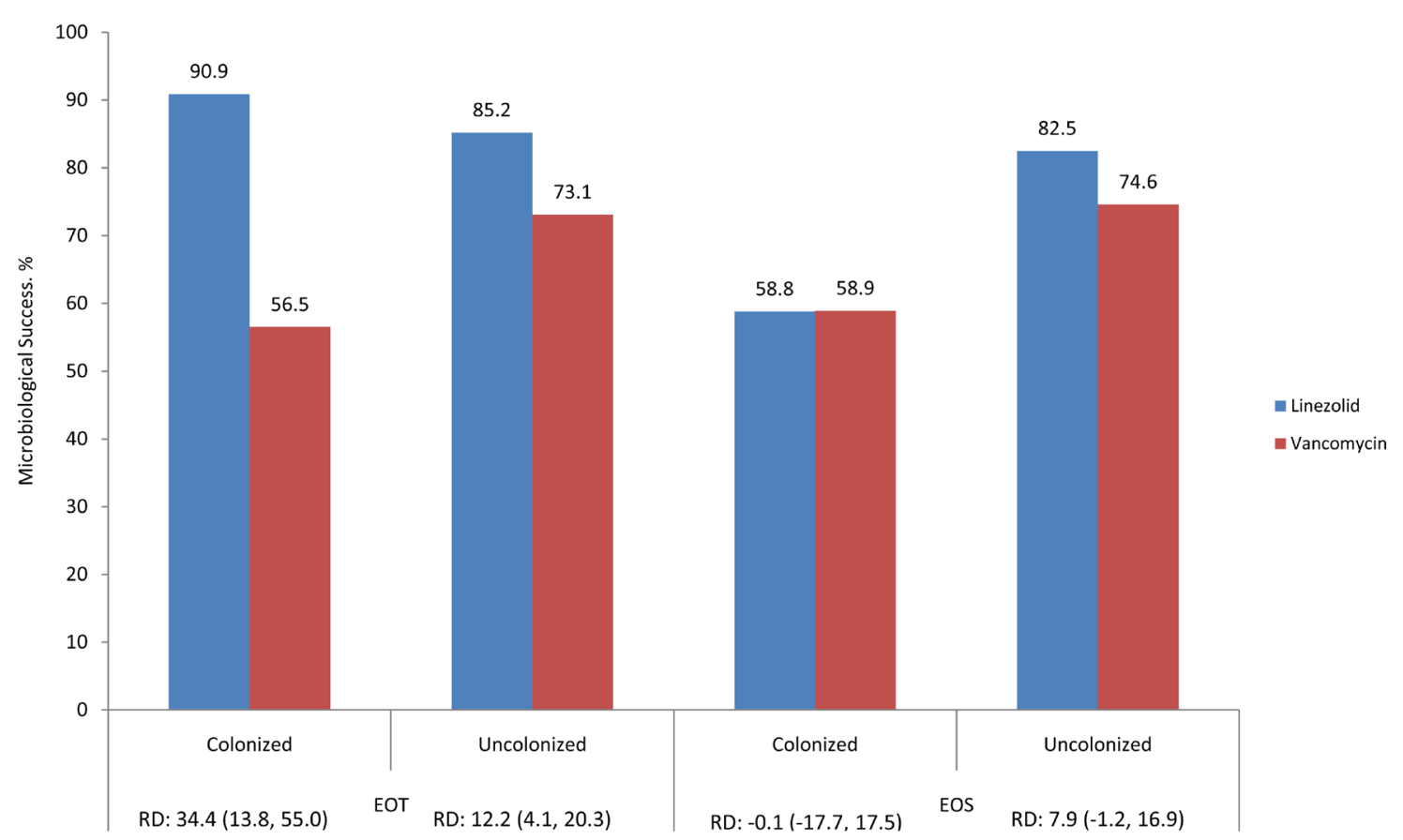

Figure 1. Microbiological success at EOT and EOS by colonization status and treatment. RD, risk difference; EOT, end of treatment; EOS, end of study.

Table 2. Predictors of MRSA colonization at end of study.

\begin{tabular}{ccc}
\hline Variable & Comparisons & Odds Ratio (95\% CI) \\
\hline Diabetes Comorbidity & Yes vs. No & $1.6(0.9,2.8)$ \\
Diagnosis & Abscess vs. Surgical Wound & $1.4(0.8,2.4)$ \\
& Abscess vs. Ulcer & $1.5(0.8,3.0)$ \\
Race & Abscess vs. Other & $7.6(2.2,25.8)$ \\
Treatment & Black vs. Non-Black & $1.9(1.0,3.3)$ \\
Vascular & Vancomycin vs. Linezolid & $1.7(1.1,2.7)$ \\
Pathogen Type & No vs. Yes & $1.5(0.9,2.5)$ \\
Gender & MRSA Mixed vs. MRSA Only & $1.6(0.9,2.7)$ \\
\hline
\end{tabular}

In our study, there were multiple predictors of MRSA colonization at end of study including type of infection, black race, MRSA mixed infection and male gender. Previous studies have shown a higher prevalence of MRSA colonization among African Americans and those with chronic conditions which is consistent with our findings [5] [23]-[28]. Treatment with vancomycin was also identified as a predictor of MRSA colonization at end of study.

Consistent with findings of other studies, we found that, patients were colonized more frequently in the nares than the groin [4] [15]-[17]. Endogenous nasal colonization is believed to be the source for most staphylococcal diseases. However, there are a growing number of studies evaluating the frequency of non-nasal colonization [4] [15] [17]. In this study there were 16 patients that had negative MRSA cultures of the nares, but had positive MRSA cultures of the groin at EOT and 34 patients at EOS. This finding highlights the potential for non-nasal colonization as a reservoir for transmission and suggests that screening and decolonization prophylaxis should be considered for the nares and groin and other potential sites for colonization (e.g. pharynx, axilla and other re- 
gions), particularly in high risk patients. There is growing evidence regarding the underestimation of MRSA colonization with a nares-only screening program and the high prevalence of non-nares MRSA colonization [4] [9] [13] [15]-[18]. A recent meta-analysis shows that approximately one third of S. aureus colonized patients would be missed with nasal screening alone [18].

This study has important limitations. First, this was a secondary analysis of an open label randomized clinical trial designed to assess efficacy and safety of treatment of MRSA cSSSI and not to evaluate the impact of colonization. By using existing data, some variables of interest were absent from the analysis. It would have been beneficial to have data regarding surgical interventions for the patients. Second, although the data was from a randomized control trial, we did not have the benefit of prospective randomization specific to our study hypotheses. However, we did find that the observed baseline characteristics were similar between linezolid and vancomycin treated patients for both those colonized and not colonized at EOS. Third, due to the original study design, we could only evaluate two time points for MRSA colonization status, EOT and EOS. It would have been beneficial to ascertain the patient's colonization status at time of infection to better understand the frequency of colonization conversion or lack of conversion between baseline and EOT and EOS. Fourth, we did not evaluate vancomycin trough levels and the relationship with colonization within the study cohorts. However, the original study reported the lack of correlation between vancomycin weight-based dosing and trough levels on microbiologic outcomes at EOT and EOS [19]. Finally, we did not have microbiological typing data available to determine the concordance of the colonizing strain and the infecting strain. This data would be beneficial in assessing the interplay between the infecting and carriage strain [26]-[29].

There are many decolonization strategies, including the use of topical and oral therapies for MRSA [4] [5] [11] [12]. However, these strategies can impact selection pressure in the microbiota and resistance tends to develop quickly [4] [29]. If there is an additional benefit to a therapeutic agent in both treating the infection and reducing colonization, it could be beneficial in interrupting horizontal transmission and recurrence of infection.

\section{Conclusion}

In this study, treatment with linezolid compared to vancomycin was associated with decreased colonization at the end of the study. By reducing carriage in patients that are infected, even if it is transient, it may reduce horizontal transmission and recurrence for that patient. Non-nasal MRSA carriage rates are important in assessing the true burden of MRSA colonization and should be considered in developing screening or decolonization strategies. Additional prospective studies evaluating the impact of MRSA colonization status on treatment and treatment impact on MRSA colonization as the primary aim are warranted.

\section{Acknowledgements}

The study was sponsored by Pfizer Inc. Programming support was provided by Diane Ruzzi, of Pfizer Inc. and statistical support was provided by Arlene Reisman. DBH and LAP were employees of Pfizer when this manuscript was developed.

\section{Disclosure Statement}

KDF is an employee and shareholder of Pfizer Inc. LAP and DBH were Pfizer Inc. employees and shareholders at the time the manuscript was developed.

\section{References}

[1] Styers, D., Sheehan, D.J., Hogan, P. and Sahm, D.F. (2006) Laboratory-Based Surveillance of Current Antimicrobial Resistance Patterns and Trends among Staphylococcus aureus: 2005 Status in the United States. Annals of Clinical Microbiology and Antimicrobials, 9, 2.

[2] Stryjewski, M.E. and Chambers, H.F. (2008) Skin and Soft-Tissue Infections Caused by Community-Acquired Methicillin-Resistant Staphylococcus aureus. Clinical Infectious Diseases, 46, S368-S377. http://dx.doi.org/10.1086/533593

[3] van Belkum, A., Melles, D.C., Nouwen, J., van Leeuwen, W.B., van Wamel, W., Vos, M.C., Wertheim, H.F. and Verbrugh, H.A. (2009) Co-Evolutionary Aspects of Human Colonisation and Infection by Staphylococcus aureus. Infection, Genetics and Evolution, 9, 32-47. http://dx.doi.org/10.1016/j.meegid.2008.09.012

[4] Abad, C.L., Pulia, M.S. and Safdar, N. (2013) Does the Nose Know? An Update on MRSA Decolonization Strategies. 
Current Infectious Disease Reports, 15, 455-464. http://dx.doi.org/10.1007/s11908-013-0364-y

[5] Ruhe, J.J., de Guzman, L., Moss, M., Riley, W., Mildvan, D., Perlman, D.C. and Koll, B. (2011) Methicillin-Susceptible Staphylococcus aureus Nasal Colonization and the Risk of Subsequent Methicillin-Resistant Staphylococcus aureus Infections among Hospitalized Patients. Diagnostic Microbiology and Infectious Disease, 71, 163-166.

http://dx.doi.org/10.1016/j.diagmicrobio.2011.05.011

[6] von Eiff, C., Becker, K., Machka, K., Stammer, H. and Peters, G. (2001) Nasal Carriage as a Source of Staphylococcus aureus Bacteremia. The New England Journal of Medicine, 344, 11-16. http://dx.doi.org/10.1056/NEJM200101043440102

[7] Wertheim, H.F., Melles, D.C., Vos, M.C., van Leeuwen, W., van Belkum, A., Verbrugh, H.A. and Nouwen, J.L. (2005) The Role of Nasal Carriage in Staphylococcus aureus Infections. The Lancet Infectious, 5, 751-762. http://dx.doi.org/10.1016/S1473-3099(05)70295-4

[8] Yamamoto, T., Nishiyama, A., Takano, T., Yabe, S., Higuchi, W., Razvina, O. and Shi, D. (2010) Community-Acquired Methicillin-Resistant Staphylococcus aureus: Community Transmission, Pathogenesis, and Drug Resistance. Journal of Infection and Chemotherapy, 16, 225-254. http://dx.doi.org/10.1007/s10156-010-0045-9

[9] Bessesen, M.T., Lopez, K., Guerin, K., Hendrickson, K., Williams, S., O’Connor-Wright, S., Granger, D. and Bunch, M. (2013) Comparison of Control Strategies for Methicillin-Resistant Staphylococcus aureus. American Journal of Infection Control, 41, 1048-1052. http://dx.doi.org/10.1016/j.ajic.2013.01.032

[10] Miller, L.G., Eells, S.J., Taylor, A.R., David, M.Z., Ortiz, N., Zychowski, D., Kumar, N., Cruz, D., Boyle-Vavra, S. and Daum, R.S. (2012) Staphylococcus aureus Colonization among Household Contacts of Patinets with Skin Infections: Risk Factors, Strain Discordance and Complex Ecology. Clinical Infectious Diseases, 54, 1523-1535. http://dx.doi.org/10.1093/cid/cis213

[11] Fritz, S.A., Camins, B.C., Eisenstein, K.A., Fritz, J.M., Epplin, E.K., Burnham, C.A., Dukes, J. and Storch, G.A. (2011) Effectiveness of Measures to Erradicate Staphylococcus aureus Carriage in Patients with Community-Associated Skin and Soft-Tissue Infections: A Randomized Trial. Infection Control and Hospital Epidemiology, 32, 972-880. http://dx.doi.org/10.1086/661285

[12] Ammerlaan, H.S., Kluytmans, J.A., Berkhout, H., Buiting, A., de Brauwer, E.I., van den Broek, P.J., van Gelderen, P., Leenders, S.A., Ott, A., Richter, C., Spanjaard, L., Spijkerman, I.J., van Tiel, F.H., Voorn, G.P., Wulf, M.W., van Zeijl, J., Troelstra, A. and Bonten, M.J., MRSA Eradication Study Group (2011) Eradication of Carriage with MethicillinResistant Staphylococcus aureus: Effectiveness of a National Guideline. Journal of Antimicrobial Chemotherapy, 66, 2418-2424. http://dx.doi.org/10.1093/jac/dkr250

[13] Ziakas, P.D., Anagnostou, T. and Mylonakis, E. (2014) The Prevalence and Significance of Methicillin-Resistant Staphylococcus aureus Colonization at Admission in the General ICU Setting: A Meta-Analysis of Published Studies. Critical Care Medicine, 42, 433-444. http://dx.doi.org/10.1097/CCM.0b013e3182a66bb8

[14] Siegel, J.D., Rhinehart, E., Jackson, M. and Chairello, L. (2007) Healthcare Infection Control Practices Advisory Committee. Management of Multidrug-Resistant Organisms in Healthcare Settings, 2006. American Journal of Infection Control, 35, S165-S193. http://dx.doi.org/10.1016/j.ajic.2007.10.006

[15] Lautenbach, E., Nachamkin, I., Hu, B., Fishman, N.O., Tolomeo, P., Prasad, P., Bilker, W.B. and Zaoutis, T.E. (2009) Surveillance Cultures for Detection of Methicillin-Resistant Staphylococcus aureus: Diagnostic Yield of Anatomic Sites and Comparison of Provider- and Patient-Collected Samples. Infection Control and Hospital Epidemiology, 30, 380-382. http://dx.doi.org/10.1086/596045

[16] Grmek-Kosnik, I., Ihan, A., Dermota, U., Rems, M., Kosnik, M. and JornKolmos, H. (2005) Evaluation of Separate vs. Pooled Swab Cultures, Different Media, Broth Enrichment and Anatomical Sites of Screening for the Detection of Methicillin-Resistant Staphylococcus aureus from Clinical Specimens. Journal of Hospital Infection, 61, 155-161. http://dx.doi.org/10.1016/j.jhin.2005.01.032

[17] Shurland, S.M., Stine, O.C., Venezia, R.A., Johnson, J.K., Zhan, M., Furuno, J.P., Miller, R.R., Johnson, T. and Roghmann, M.C. (2009) Colonization Sites of USA300 Methicillin-Resistant Staphylococcus aureus in Residents of Extended Care Facilities. Infection Control and Hospital Epidemiology, 30, 313-318. http://dx.doi.org/10.1086/596114

[18] McKinnell, J.A., Huang, S.S., Eells, S.J., Cui, E. and Miller, L.G. (2013) Quantifying the Impact of Extranasal Testing of Body Sites for Methicillin-Resistant Staphylococcus aureus Colonization at the Time of Hospital or Intensive Care Unit Admission. Infection Control and Hospital Epidemiology, 34, 161-170. http://dx.doi.org/10.1086/669095

[19] Itani, K.M., Dryden, M.S., Bhattacharyya, H., Kunkel, M.J., Baruch, A.M. and Weigelt, J.A. (2010) Efficacy and Safety of Linezolid versus Vancomycin for the Treatment of Complicated Skin and Soft-Tissue Infections Proven to Be Caused by Methicillin-Resistant Staphylococcus aureus. The American Journal of Surgery, 199, 804-816. http://dx.doi.org/10.1016/j.amjsurg.2009.08.045

[20] Gee, T., Ellis, R., Marshall, G., Andrews, J., Ashby, J. and Wise, R. (2001) Pharmacokinetics and Tissue Penetration of Linezolid Following Multiple Oral Doses. Antimicrobial Agents and Chemotherapy, 45, 1843-1846. 
http://dx.doi.org/10.1128/AAC.45.6.1843-1846.2001

[21] Stein, G.E. and Wells, E.M. (2010) The Importance of Tissue Penetration in Achieving Successful Antimicrobial Treatment of Nosocomial Pneumonia and Complicated Skin and Soft-Tissue Infections Caused by Methicillin-Resistant Staphylococcus aureus: Vancomycin and Linezolid. Current Medical Research and Opinion, 26, 571-588. http://dx.doi.org/10.1185/03007990903512057

[22] Rybak, M.J., Lomaestro, B.M., Rotschafer, J.C., Moellering Jr., R.C., Craig, W.A., Billeter, M., Dalovisio, J.R. and Levine, D.P. (2009) Therapeutic Monitoring of Vancomycin in Adults Summary of Consensus Recommendations from the American Society of Health-System Pharmacists, the Infectious Diseases Society of America, and the Society of Infectious Diseases Pharmacists. Pharmacotherapy, 29, 1275-1279. http://dx.doi.org/10.1592/phco.29.11.1275

[23] Chen, C.C. and Pass, S.E. (2013) Risk Factors for and Impact of Methicillin-Resistant Staphylococcus aureus Nasal Colonization in Patients in a Medical Intensive Care Unit. American Journal of Infection Control, 41, 1100-1101. http://dx.doi.org/10.1016/j.ajic.2013.01.035

[24] Stevens, A.M., Hennessy, T., Baggett, H.C., Bruden, D., Parks, D. and Klejka, J. (2010) Methicillin-Resistant Staphylococus aureus Carriage and Risk Factors for Skin Infections, Southwestern Alaska, USA. Emerging Infectious Diseases, 16, 797-803. http://dx.doi.org/10.3201/eid1605.091851

[25] Patel, M., Weinheimer, J.D., Waites, K.B. and Baddley, J.W. (2008) Active Surveillance to Determine the Impact of Methicillin-Resistant Staphylococcus aureus Colonization on Patients in Intensive Care Units of a Veterans Affairs Medical Center. Infection Control and Hospital Epidemiology, 29, 503-509. http://dx.doi.org/10.1086/588161

[26] Varshney, A.K. (2010) Augumented Production of Panton Leukocidin Toxin in Methicillin-Resistant and Susceptible Staphylococcus aureus Is Associated with Worse Outcome in Murine Skin Infection Model. The Journal of Infectious Diseases, 201, 92-96. http://dx.doi.org/10.1086/648613

[27] Lopez, M.B., Gonzalez, C.G., Orellana, M.A., Chaves, F. and Rojo, P. (2013) Staphylococcus aureus Abscesses: Methicillin-Resistance or Panton-Valentine Leukocidin Presence? Archives of Disease in Childhood, 98, 608-610. http://dx.doi.org/10.1136/archdischild-2012-302695

[28] Huang, D.B., Reisman, A. and Hogan, P. (2010) Clinical Outcomes by Methicillin-Resistant Staphylococcus aureus Staphylococcal Cassestte Chromosome Mec Type: Isolates Recovered from a Phase IV Clinical trial of Linezolid and Vancomycin for Complicated Skin and Skin Structure Infections. Antimicrobial Agents and Chemotherapy, 54, 40364037. http://dx.doi.org/10.1128/AAC.00044-10

[29] Frank, D.N., Feazel, L.M., Bessesen, M.T., Price, C.S., Janoff, E.N. and Pace, N.R. (2010) The Human Nasal Microbiota and Staphylococcus aureus Carriage. PLoS One, 17, e10598. 
Scientific Research Publishing (SCIRP) is one of the largest Open Access journal publishers. It is currently publishing more than 200 open access, online, peer-reviewed journals covering a wide range of academic disciplines. SCIRP serves the worldwide academic communities and contributes to the progress and application of science with its publication.

Other selected journals from SCIRP are listed as below. Submit your manuscript to us via either submit@scirp.org or Online Submission Portal.
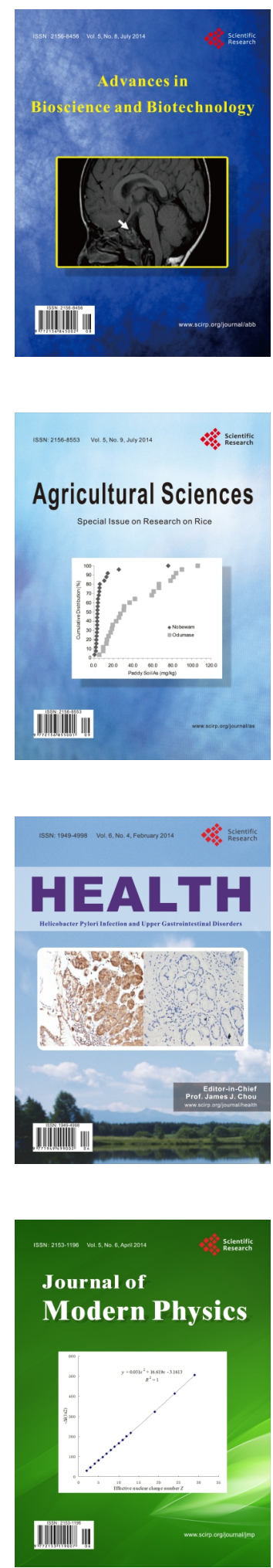
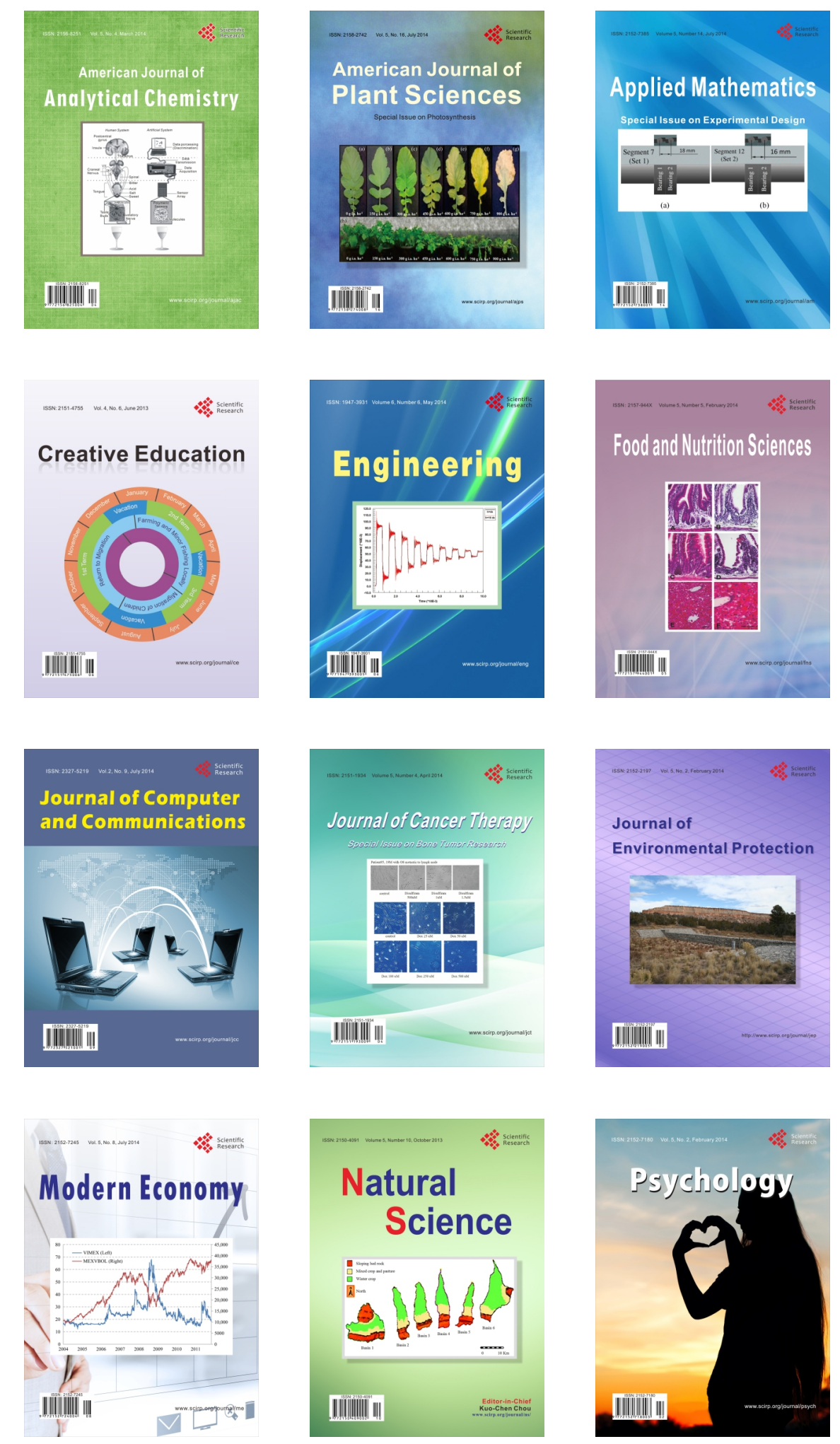